Research Article

\title{
Forecasting of Hazard Zone due to Storm Surge Using SIND Model
}

\author{
Dong Hyun Kim $\mathbb{D}$, Hyung Ju Yoo, and Seung Oh Lee $\mathbb{D}$ \\ Department of Civil Engineering, Hongik University, Seoul 04066, Republic of Korea \\ Correspondence should be addressed to Seung Oh Lee; seungoh.lee@gmail.com \\ Received 11 September 2020; Accepted 7 May 2021; Published 21 May 2021 \\ Academic Editor: Haiyun Shi
}

Copyright (C) 2021 Dong Hyun Kim et al. This is an open access article distributed under the Creative Commons Attribution License, which permits unrestricted use, distribution, and reproduction in any medium, provided the original work is properly cited.

\begin{abstract}
We have developed the SIND (scientific interpolation for natural disasters) model to forecast natural hazard zone for storm surge. Most previous studies have been conducted to predict hazard zone with numerical simulations based on various scenarios. It is hard to predict hazard zone for all scenarios and to respond immediately because most numerical models are requested a long simulation time and complicated postprocess, especially in coastal engineering. Thus, in this study, the SIND model was developed to overcome these limitations. The principal developing methods are the scientific interpolation for risk grades and trial and error for parameters embedded in the governing equation. Even designed with hatch files, applying disaster characteristics such as the risk propagation, the governing equation for storm surge in coastal lines was induced from the mathematical solver, COMSOL Multiphysics software that solves partial differential equations for multiple physics using FEM method. The verification process was performed through comparison with the official reference, and the accuracy was calculated with a shape similarity indicating the geometric similarity of the hazard zone. It was composed of position, shape, and area criteria. The accuracy of about $80 \%$ in terms of shape similarity was archived. The strength of the model is high accuracy and fast calculation time. It took only less than few seconds to create a hazard map for each scenario. As future works, if the characteristics of other disasters would be understood well, it would be able to present risk propagation induced from each natural disaster in a short term, which should help the decision making for EAP.
\end{abstract}

\section{Introduction}

With the increasing extreme disasters including drought, heavy rain as well as ground heat, the ability to predict hazardous area affected by them has become more important. In the case of urban areas, man-made spaces were built such as impervious and underground spaces. These resulted in increasing the damage by natural disaster. Thus, many research studies have been carried out to respond to these extreme climate changes. Disaster measures to prevent extreme climate change can be divided into structural and nonstructural measures. In particular, the nonstructural measures generally include estimating the range or degree of each damage under various scenarios. Among them, a scenario-based hazard map is mainly made by governments and local public institutions to inform hazardous area to the residents.
In Korea, recently nonstructural measures have been taken to prevent natural disasters since there are many restrictions on structural measures such as land use, environmental effect, and so on. From the past, studies on countermeasures have been carried out, and the process of disaster damage to the area has been suggested by Cutter [1] and Lindell and Prater [2]. In Korea, the National Institute for Disaster Prevention [3] conducted a study on regional risk assessment and application for disaster management. The Seoul Institute [4] developed evaluation methods to prevent urban disasters in Seoul, Korea. Regarding coastal disasters, many countries have developed autonomously flood forecasting and disaster planning techniques to predict and respond to disasters. The NOAA (National Oceanic and Atmospheric Administration) is building a forecasting system for monitoring and supervising storm surges and tsunamis. In the United States Army Corps of Engineers, the 
White Paper on Estimating Hurricane Inundation Probability (Hurricane Inundation Probability) is used to describe the storm events, the empirical simulation method, the empirical track model, and so on. In Japan, the Meteorological Agency has been building a remote magnetic detection device update and forecasting system to quickly and accurately grasp tsunami. It is constantly monitoring tsunami and storm surge throughout many countries. In addition, the local government area focusing on public relations by creating a coastal hazard map indicates areas and evacuation routes according to the intensity of typhoons. Meanwhile, numerical simulation has been the most essential element for making such hazard map.

It has been actively carried out on past disasters and virtual disaster scenarios in order to produce a hazard map. Scenarios of coastal disasters involve earthquakes and typhoons. However, since it is difficult to predict earthquakes and typhoons, most scenarios for the global scale are constructed based on past cases. It is not realistic to consider all parameters of typhoon which occurred in the global scale. It is not realistic to consider all parameters of typhoon which occurred in the global scale because of the diversity of sizes and routes of typhoons and the lack of numerical simulation capability and DB. Thus, the studies related to numerical simulations have been carried out continuously for forecasting risk. To forecast the inundation caused by the storm surge, it is important to calculate the initial wave height. The initial tidal-wave computation studies began in the mid1990s, with brief empirical formulas based on observations (Conner et al. [5]; Harris [6]) or interpretations applied to simple waters (Proudman [7]; Doodson [8]; Heaps [9]). The development of high-performance computers could lead to numerical calculations of the governing equations in the 1960s, followed by a more detailed three-dimensional numerical model. Since the mid-1970s, numerical analysis on the theory and mechanism of storm surge have progressed in earnest, and simulation studies about spatial and temporal sea surface changes have begun (Simpson and Riehl [10]; Murty [11]; Pugh [12]). And the interpretation of sea level fluctuations requires an understanding of the action of complex oceanic elements such as tides, waves, oceanic winds, and sea surface pressure, and the importance of nonlinearity in relation to each element has been proposed by many researchers (Heaps [13]; Wolf et al. [14]; Tolman, [15]; Mastenbroek et al. [16]). The numerical simulations considering the interaction between the wave model and the storm surge model have been carried out in $\mathrm{Li}$ and Zhang [17] and Ozer et al. [18]. In addition, Peng et al. [19] analyzed the characteristics of storm surge and inundation according to changes of central air pressure, wind speed, and moving speed of each route after selecting 10 virtual storms in North Carolina Sea. There are various factors to define or simulate the inundation due to even single a storm surge. It is practically impossible to consider all of them, and also it heavily depends on the numerical simulation technique with various assumptions and boundary conditions.

On the other hand, in the step of disaster response, it is very important to simulate and analyze the initial wave height for making the hazard map. For this purpose, several considerations should be realized and computed in the numerical model such as the complexity of tidal, storm surge, and high waves, the effect of bottom friction in coastal submergence, and the smooth moving boundary layer calculation technique. There have been many cases related to flooding in coastal areas due to boundary and initial conditions on the outer seaside (Bates and De Roo [20]; Nicholls [21]; Brown [22]; Purvis et al. [23]). However, these models have many restrictions such as the calculation time with respect to corresponding accuracy. It is difficult to estimate the damage scenarios that do not exist and to forecast in a short time because the simulation time of most disaster prediction programs takes a long time. Brown [22] applied a rule-based method based on the geographic information system to derive future hazard areas due to large-scale climate change. The rule-based method enables rapid flood risk assessment compared with the hydrodynamic model. It could not consider the hydrodynamical effects such as storm surge. Therefore, in this study, we propose a methodology to produce hazard map of storm surge by the interpolation method using hazard map based on the hydrodynamic model.

In the field of weather and climate forecasting, the interpolation method has been traditionally used to estimate data for unmeasurable areas using statistical techniques such as spatial interpolation. It is meaningful in that it can provide a very good alternative method for estimating local phenomena with a small number of observational samples. However, it has a limitation that depends only on the number or values of available observed data. Many studies have been conducted to reduce the uncertainty and increase the accuracy of their estimations by using additional data that can reflect natural and physical characteristics to supplement these limitations (Yim and Lee [24]).

For instance, representative results of cokriging, when utilizing the altitude above sea level related to temperature, are compared with the estimation results of kriging, a traditional spatial interpolation method. Ishida and Kawashima [25] compared results from the cokriging method with the estimations of the kriging method in terms of the elevation above sea level which is a geographical climate factor highly related to temperature. Finally, it was found that the estimation results of the cokriging showed higher accuracy.

Fitria [26] used the interpolation method to analyze the spatial distribution of inundation according to initial tsunami heights. Several researchers also developed the interpolation techniques to determine the tsunami hazard zones (Islam et al. [27]; Maemunah et al. [28]; Fitria [26]). These researches also applied geostatistical approach through spatial interpolation with the kriging method. Fauzi and Mayasari [29] designed a tsunami hazard zone based on land use, slope, and distance from the shoreline using spatial modelling with GIS via the ordinary kriging method. However, the verification of the kriging model by the interpolation method was practically difficult, and there was a limit that the accuracy of such model cannot be evaluated.

Therefore, in this study, a model was developed using the interpolation method, and a shape similarity was introduced to quantitatively verify it. It was estimated for accuracy by 
verifying the official hazard map and added physical meaning to the model by using additional data such as the characteristics of storm surge and the topography of the study area. Using this model, hazardous areas and risks are provided in a short time according to user-defined conditions so that a disaster situation can be determined as much as precisely for decision or policy maker.

\section{Methodology}

2.1. Scientific Interpolation and SIND Model. The SIND model was developed by using the interpolation method with the governing equation expressed by a partial differential equation (PDE). Interpolation is widely used in the various fields of mathematics, economics, medicine, meteorology, and engineering. For example, it is used to perform surface modelling or numerical topography modelling and to express linearly new data points. It has been used to understand the spatial structure of the target object and to design artificial organs which implanted in the human body. Also, it is known to simulate operation plan in the medical field (Lee [30]). The method from this study calculates new data with old data such as observation data and field measurements after establishing physical understanding, which is why we used "scientific" interpolation method. In detail, there are 3 reasons to explain that the "scientific" interpolation method was used in this study. First, the governing equation is not a simple PDE for a linear interpolation. It implies the meaning of risk transfer, of which form is similar to the heat transfer equation. Next, the transfer of risk grade depends on the topographical characteristics in the research area, which are embedded in the risk transfer equation. Finally, the input and boundary conditions are also defined by reflecting the physical characteristics of the storm surge after risk analysis was performed.

There are 3 steps to develop the SIND model as presented in Figure 1. First, the analysis of the hazard map is required to extract the main factor for each disaster. For storm surges, the hazard map was made by the government (MLTMA [32]) along the coastal line in Korea. However, they have only 4 hazard maps of each condition. This means that it could not predict the risk except the 4 wave height conditions. Next, the governing equation was derived using the hazard maps, and coefficients of the equation were decided by the trial and error method. Thus, this new prediction model for natural disaster can estimate the damage due to disaster with all conditions. Finally, it was verified by shape similarity and mounted on the disaster prediction system (see Figure 1). Since this equation is based on a database, the more reference data are accumulated, more accurate equation we can get. The component of the model was divided into "Activation Conditions" and "Usage Conditions." Each solver is performed based on these conditions. The users selected the degree or characteristics of disaster they want at the "Activation Conditions" (see Figure 1).

For a storm surge, the users can input conditions such as typhoon route, wind strength, and typhoon intensity, which are already selected by users as primary input variables. If they would set these conditions, the model would start to search the prebuilt database to check if there is the same condition of the data that they want. If not, the governing equation for prediction would be loaded. And the conditions entered by the user become a reference value for selecting the governing equation set for each condition in the "Usage condition" (see Figure 2), and the risk prediction is performed by the selected equation. All outcomes from this step are automatically stored in the database. In this model, the prediction accuracy of the risk is dominant by the selected equation for which we used the commercial program COMSOL Multiphysics to do the trial and error method.

\subsection{Derivation of Governing Equation for Storm Surge.} The derivation of governing equations for each disaster is the most important process to develop this model. First, we must analyze the hazard maps for disaster scenarios after collecting hazard maps related to the storm surge in Korea. They were computed with numerical models and presented by government (MLTMA [32]), and they officially have 4 maps with 4 conditions (see Table 1). These conditions are corresponding with the frequency of wave height caused by the typhoon in coastal area, 50-year, 100-year, 150-year, and 200-year wave height. The numerical model, KOSY (Kordi Operational Storm surge prediction sYstem) (MLTMA [32]), used to compute the wave height is basically a hydrodynamic model and includes the meteorological conditions of typhoons. It is an extension of the tidal model by the fractional step method and applied the shear stress caused by wind at the air-sea interface. Also, it is able to consider the horizontal pressure due to the spatial distribution of atmospheric pressure, the method of solving the long wave equation in which the momentum equation is vertically integrated. The size of the horizontal grid is about $300 \mathrm{~m}$ at the offshore and approximately $9 \mathrm{~km}$ at the open sea, respectively. The most basic and important factor in calculation of wave height is the establishment of precise bathymetry data. This is established by collecting data from the National Oceanographic Research Institute and global bathymetry data such as GEBCO 08, ETOPO1, and ETOPO2 of which horizontal resolution of these data is about $500 \mathrm{~m} \sim 2 \mathrm{~km}$. The time step of the numerical model is $1 / 3 \mathrm{sec} \sim 3 \mathrm{sec}$ depending on the grid size.

The interpolation generally needed 3 reference data at least. So, we used the 3 maps to derive governing equation to predict risk grades for storm surge, 50-year, 150-year, and 200 -year wave height. The other was used for verification of equation, 100-year wave height.

First, the basic form of equation was derived with physical meaning considering some assumptions. And the coefficients of the equation and boundary conditions were defined by the trial and error method. An independent variable of equation is set as the wave height frequency, and a dependent variable is the spatial distribution of the risk grades. Results from this model were put in the same conditions (50-year, 150-year, and 200-year wave height) with hazard map was compared with them to check whether this equation can exactly predict spatial distribution of risk 


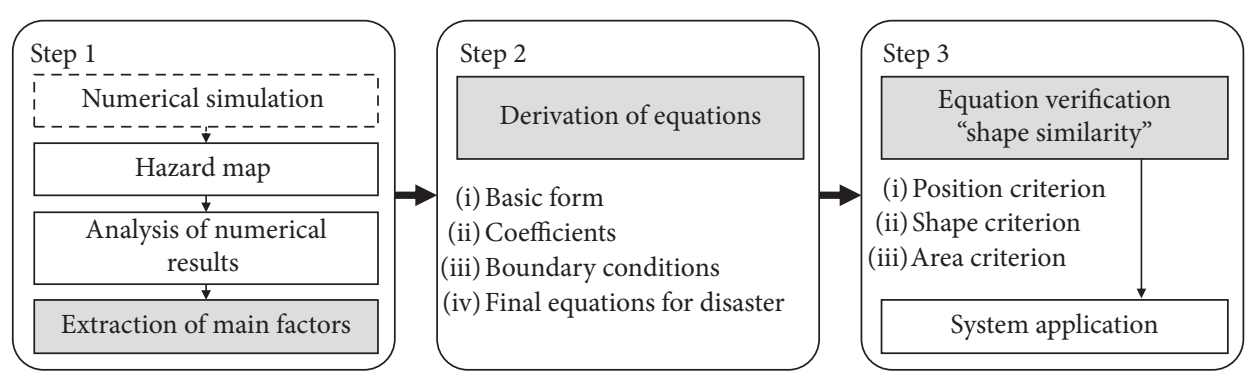

Figure 1: Progress of the SIND model (Kim et al. [31]).

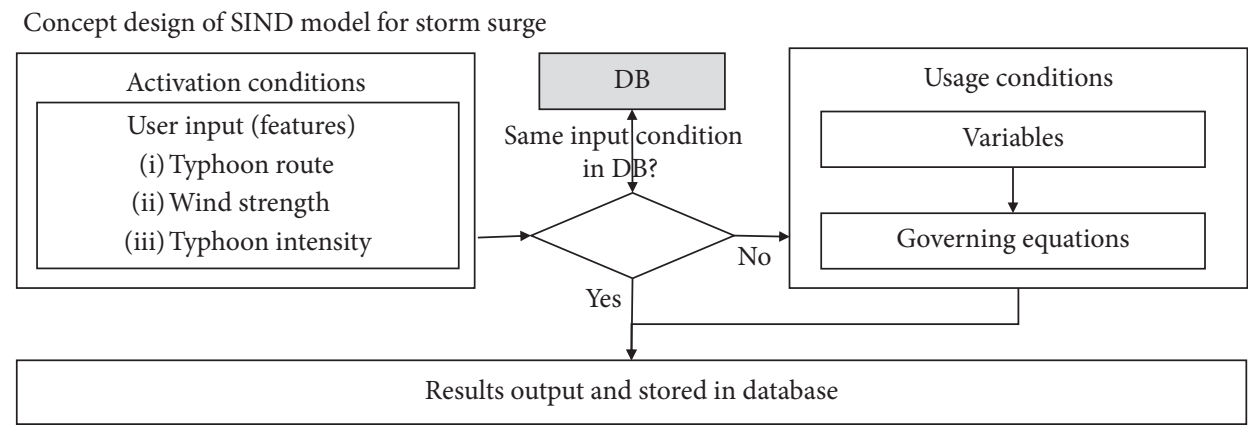

Figure 2: Concept design of the SIND model.

TABLE 1: Information of hazard maps.

\begin{tabular}{lc}
\hline & Hazard map \\
\hline Format & Shape file (.shp), AutoCad file (.dxf, .dwg) \\
Agent & MLTMA (the Ministry of Land, Transport, and Maritime Affairs) \\
Program & Numerical model (physical model) \\
Year & 2010 \\
Conditions & 50-year, 100-year, 150-year, 200-year \\
\hline
\end{tabular}

grade. The COMSOL Multiphysics program was used to perform the trial and error method for determining the equations and comparing the results. And the shape similarity was used to estimate accuracy of prediction by comparison of inundated area with official hazard map. Finally, the governing equation for predicting the risk of storm surges was derived (see Figure 3 ). After that, the result obtained using the same input conditions as the other map (100-year frequency) was compared with that of the map to verify the final equation.

\subsubsection{COMSOL Multiphysics (Ver. 5.4). COMSOL Multi-} physics developed by COMSOL AB (Multiphysics [33]) was used to derive governing equations for storm surges. COMSOL Multiphysics is a software that solves partial differential equations for multiple physics using the FEM method. The users can construct their own model and configure each part to enter or adjust values instantly. So, they can derive the equation with the change of conditions to make what they need. In other words, the property and boundary condition can be set as any function including space-time and dependent variables. COMSOL Multiphysics is equipped with governing equations that are frequently used in the various fields of the heat transfer, flow, electromagnetic, structure, acoustic, chemical reactions, and equation-based module. Equation-based module allows users to construct their own governing equations to derive results. Nonlinear PDE-type equations can be classified into three types: coefficient form, general form, and weak form. In this study, coefficient form was used as follows:

$$
e_{a} \frac{\partial^{2} u}{\partial t^{2}}+d_{a} \frac{\partial u}{\partial t}-\nabla \cdot(c \nabla u+\alpha u-\gamma)+\beta \cdot \nabla u+a u=f
$$

where $e_{a}$ is the mass coefficient, $d_{a}$ is a damping coefficient or mass coefficient, $c$ is the diffusion coefficient, $\alpha$ is the conservative flux convection coefficient, $\beta$ is the convection coefficient, $a$ is the absorption coefficient, $\gamma$ is the conservative flux source term, and $f$ is the source term.

On the left-hand side of equation (1), it consists of terms of time, diffusion, convection, source, and absorption. It indicates a source term which can be used or selected according to the condition on the right-hand side. The users should select the coefficients $c, \alpha, \gamma, \beta$, and $a$ and the boundary $\operatorname{term} f$. 


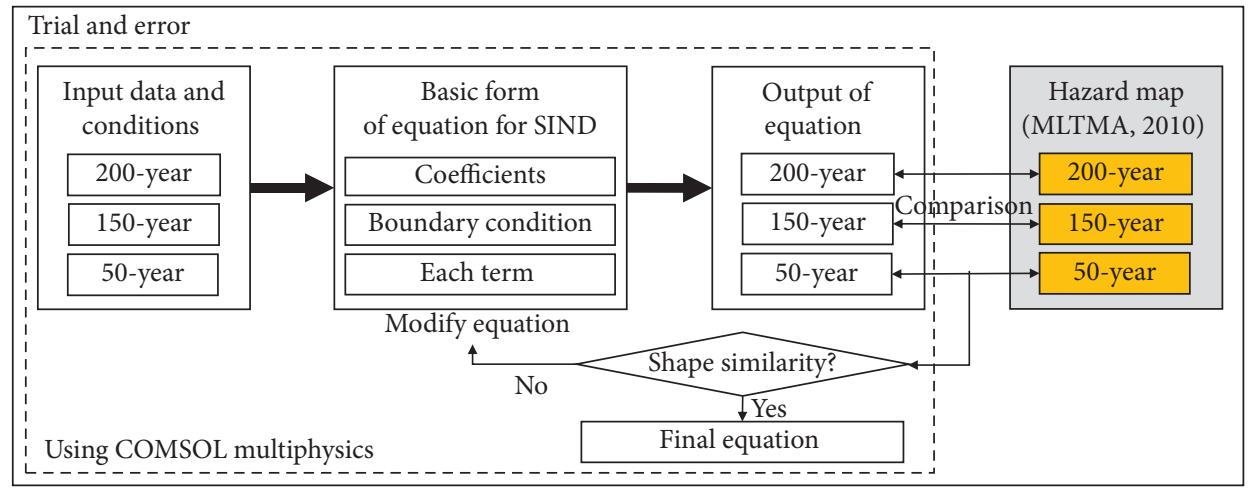

Figure 3: Process of derivation equation for storm surge in the SIND model.

2.2.2. Basic Form of Equation for Storm Surge. The risk grade for storm surge is based on the maximum inundation depth according to the typhoon grade. The hazard map is used as the database showing the maximum inundation depth in the coastal areas regardless of the occurrence time (MLTMA [32]). The risk propagation as the frequency of wave height is assumed that the absorption term is not significant. There is another assumption meaning that the initial risk grade determined by the typhoon grade is transmitted through the mediators such as geographical features. This mechanism is similar to the heat transfer equation. Thus, the governing equation for storm surge is shown compared with the heat transfer equation in Table 2.

The parameters of Table 2 are put in the coefficient form provided by COMSOL. Then, we assumed this equation as a steady state because it cannot consider the change over time due to the characteristics of the hazard map. Finally, eliminating the time term, the equation can be expressed as

$$
\nabla \cdot(-k \nabla D)=Q
$$

where $D$ is a risk grade and $k$ is a resistance coefficient.

2.2.3. Assumptions. The coefficient required by the basic form is the resistance coefficient $k$ and the boundary conditions which are the risk grade $D_{0}$ for coastal areas and $D_{\text {ext }}$ for in land areas. An inundation caused by storm surge depends on the terrain characteristics. Thus, the resistance coefficient should be reflected to elevation (DEM). DEM provided by the National Geographic Information Institute in Korea was used to cover land topography with the scale of the DEM of $1: 5000$ and the grid size of $5 \mathrm{~m}$. The wave height with frequency is the most important factor and boundary condition affecting inundation. The calculations of wave height can generally take into account the effects of tide, wind, and pressure fluctuations. The wave height used in the SIND model was calculated by considering the path, wind speed, and wind field of 201 typhoons for 56 years from 1951 to 2006. Wave heights were calculated according to each frequency with the KOSY. It is determined by typhoon grade and calculated as an initial risk grade on the boundaries. A regression analysis was performed to estimate the initial risk grades conditions for all scenarios, using 3 conditions of frequency (50-year, 150-year, and 200-year). The risk grades on the land boundary are defined as the distance from the coast. The assumptions for the coefficients and each boundary condition are as follows:

(i) The resistance coefficient depends on the topographical conditions of the coastal area

(ii) Resistance constant $(k)$ is inversely proportional to elevation (DEM)

(iii) The risk grade $\left(D_{0}\right)$ at the coastal boundary depends on the grade of the typhoon and the wave height

(iv) The risk grade $\left(D_{\text {ext }}\right)$ at the land boundary is lower as the distance from the coast increases

2.3. Validation of SIND Model with Shape Similarity. The hazard map depicts the hazardous areas and risk grades with inundation depth according to storm surge conditions. The area and location of the flooded zones are important factors and related to the shape of inundated zones. The comparison of shape of inundated area with the flooded zone in hazard map should be conducted to examine the accuracy of this SIND model. As a result, it is necessary to compare the position and shape of inundation areas to verify the result from the SIND model. It introduced the shape similarity method to quantify how much similar two figures or maps by comparing in their positions, shapes, and areas. It can express the degree of similarity using the geometrical properties of the spatial dataset. However, it does not consider the risk grades because it can just compare twodimensional figures in terms of geometry only. To consider the risk grades, the hazardous areas for each risk grade were divided and compared again with the graded flood zone in hazard map. Thus, the shape similarity with risk grade is most efficient way to verify the results and to determine accuracy. Kim et al. [34] used a CRITIC method, one of the methods of calculating shape similarity, to select a matching criterion that can reflect geometric properties. The criteria for the similarity of spatial data are the position criterion that means the distance between the center of gravity and shape criterion that uses the shape index. An area criterion uses the ratio of overlapped areas (see Figure 4). For example, in Figure 4(a), when A is the result of hazard map and B is the result of SIND Model, two figures overlap each other based on a certain point. After that, the shape similarity is 
TABLE 2: SIND for storm surge in coefficient form.

\begin{tabular}{lcr}
\hline Parameter & Heat transfer & Risk grade for storm surge \\
\hline$U$ & Temperature, $T$ & Risk grade (inundation), $D$ \\
$e_{a}$ & 0 & 0 \\
$d_{a}$ & $\rho C_{a}$ & 1 \\
$C$ & Conductivity coef. $-k$ & Resistance coef. $-k$ \\
$\gamma$ & 0 & 0 \\
$\beta$ & Velocity & Velocity \\
$\alpha$ & 0 & 0 \\
$F$ & Heat flux, $Q$ & Risk flux, $Q$ \\
\hline
\end{tabular}

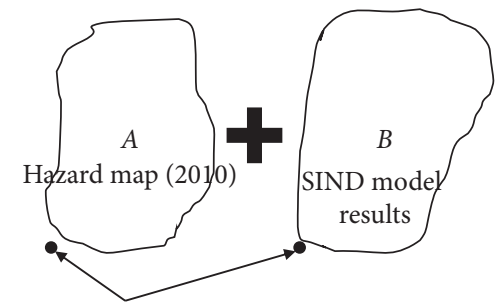

Points of standard

(a)

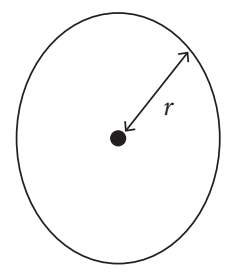

$S I=1$
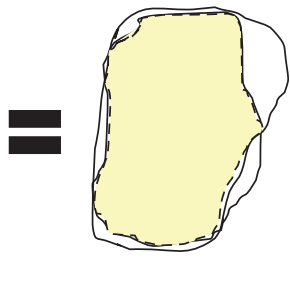

gravity

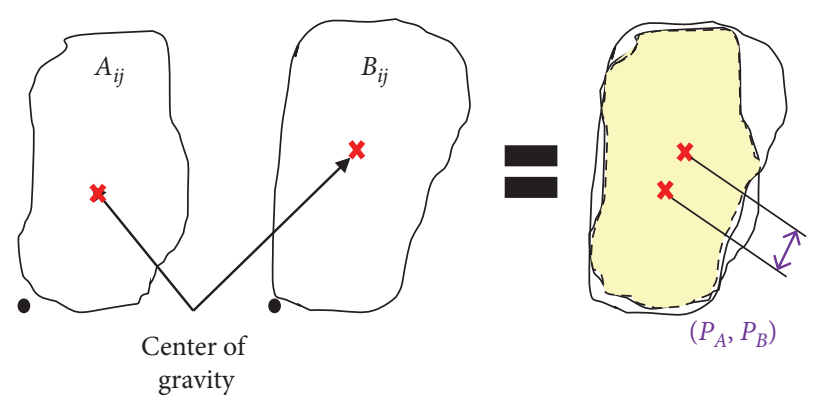

(b)

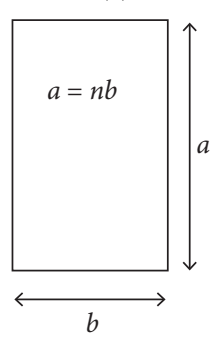

(c)
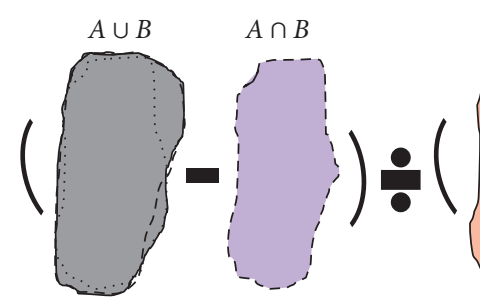

(d)

FIGURE 4: Concept of the CRITIC method. (a) Matching coupled object. (b) Position criterion: center of gravity. (c) Shape criterion: shape index. (d) Area criterion: ratio of overlapped area.

calculated using the location criteria (see Figure 4(b)), shape criteria (see Figure 4(c)), and area criteria (see Figure 4(d)).

2.3.1. Position Criterion (SP). The position criterion is evaluated as the distance between the centers of gravity of two objects. The closer the position criterion is to 1.0 , the more similar the object of the SIND model is to the hazard map.

$$
\mathrm{SP}=1-\frac{P_{c}-P_{m}}{P_{m}}(0 \leq S P \leq 1),
$$

where $P_{m}$ is $\sqrt{\left(X_{m}-X_{s}\right)^{2}+\left(Y_{m}-Y_{s}\right)^{2}}$ and $P_{c}$ is $\sqrt{\left(X_{c}-X_{s}\right)^{2}+\left(Y_{c}-Y_{s}\right)^{2}} . X_{m}$ and $Y_{m}$ are the center of gravity for the hazard map, and $X_{c}$ and $Y_{c}$ are the center of gravity for the SIND model.
2.3.2. Shape Criterion (SR). The CRITIC method is mainly used in GIS-based mapping field, and the shape of object is close to basic shape like rectangle and circle. There is a limitation to using this method because the shape of the hazardous area for storm surge shows a thin and long band shape. Thus, this method was modified by adding the RCCI index that can apply the elongated shape.

$$
\begin{aligned}
\mathrm{SR}-I & =1-\frac{R_{c}-R_{m}}{R_{m}}(0 \leq \mathrm{SR}-I \leq 1), \\
\mathrm{SR}-I I & =1-\frac{\mathrm{RCCI}_{c}-\mathrm{RCCI}_{m}}{\mathrm{RCCI}_{m}}(0 \leq \mathrm{SR}-I I \leq 1), \\
\mathrm{SR} & =s_{1} \times \mathrm{SR}-I+s_{2} \times \mathrm{SR}-I I(0 \leq \mathrm{SR} \leq 1),
\end{aligned}
$$

where $R_{m}$ is $\left|P_{m} /\left(2 \sqrt{\pi A_{m}}\right)\right|$ and $R_{c}$ is $\left|P_{c} /\left(2 \sqrt{\pi A_{c}}\right)\right| . P_{m}$ is the perimeter of the shape in hazard map. $P_{c}$ is the perimeter in the SIND model. RCCI is added shape index. Equation is 
RCCI $=|A / C A| . A_{c}$ and $A_{m}$ are area of each shape. CA is circumscribed circle area. $s_{1}$ and $s_{2}$ are weights of 0.4 and 0.6 , respectively.

2.3.3. Area Criterion (SA). The area criterion was estimated using the ration of overlapped area between 2 maps.

$$
S A=1-\left|\frac{\left(A_{c} \cup A_{m}\right)-\left(A_{c} \cap A_{m}\right)}{A_{m}+A_{c}}\right|(0 \leq S A \leq 1),
$$

where $A_{m}$ is the inundation area in hazard map and $A_{c}$ is the inundation area in the SIND model.

2.3.4. Overall Shape Similarity (S). The weights are calculated using the information amount and the correlation coefficient. The closer each criterion (SP, SR, and SA) is to 1.0, the overall shape similarity has higher value. That means the overall shape similarity $(S)$ of the matching object is close to 1.0 .

$$
S=w_{1} \times \mathrm{SP}+w_{2} \times \mathrm{SR}+w_{3} \times \mathrm{SA}(0 \leq S \leq 1)
$$

where $w_{1}, w_{2}$, and $w_{3}$ are the respective weights.

\section{Results and Discussion}

3.1. Coefficients and Boundary Conditions of SIND Model. Using the trial and error method, the resistance coefficient $(k)$, the risk grade $\left(D_{\text {ext }}\right)$ at the land boundary, and the initial risk grade $\left(D_{0}\right)$ at the coast boundary were calculated. The calculated coefficient and boundary conditions are considered with the characteristics of storm surge through assumptions. According to the assumptions, the distribution of $k$ has something to do elevation (see Figures 5(a) and $6(\mathrm{a})$ ). If $k$ had low value, the propagation of risk is easier. The correlation is shown in the following equation:

$$
k=\frac{c_{1}}{z}
$$

where $c_{1}$ is the empirical coefficient to be 0.5 and $z$ is the elevation.

As shown in Figure 5(b), boundary conditions can be divided into coastal and land. The coastal boundary conditions used the wave height at the station through frequency analysis in the MLTMA report (see equation (8)). There is a restriction that all boundaries were estimated as 1 representative point. So, sections of boundary were divided according to the risk grade on the hazard map (see Figure 5(c) and Figure 4(d)). The wave height for storm surge was calculated through regression analysis to deal with all frequencies (see Figure 6(c)). The regression equation of the boundary condition in coastal line is shown in equation (9) and Figure 6(d). The risk grade of land boundary is expressed as distance $d$ with the coastline, as shown in equation (10) and Figure 6(b):

$$
\begin{aligned}
H & =0.235 \ln (T)+0.128, \\
D_{0} & =c_{2}(4.25 H-0.54)+c_{3} \\
D_{\text {ext }} & =c_{4} d
\end{aligned}
$$

in coastal line boundary, in land boundary,where $T$ is frequency of wave height, $H$ is the wave height, $c_{2}$ is equivalent to 2.525 in sections $\mathrm{A}$ and $\mathrm{B}, c_{3}$ is -1.293 in section $\mathrm{A}$ and -5.293 in section $\mathrm{B}, c_{4}$ is constant, $0.25, c_{2}, c_{3}$, and $c_{4}$ are empirical coefficients, and $d$ is the distance from coastal line.

3.2. Results of Derivation Process. The reference value is the criterion which determines similarity between the result of the equation and the hazard map. This value is 0.6 , and it is used in the GIS-based mapping field. When the shape similarity is 0.6 or more, it is estimated that the results in the SIND model are implemented well. The detailed results are shown in Table 3. The results with each frequency are shown in Figure 7. The matching pairs above 0.6 are $73.7 \%, 62.0 \%$, and $66.7 \%$, respectively.

3.3. Short-Term Forecasting Hazard Zone. The SIND model can predict the hazardous area caused by storm surges in a short time with simple input conditions. Table 4 shows the geometric results of each hazardous area. The result was very similar to the inundation area shape of the hazard map. However, the locally generated error between the two shapes is because the regional characteristics were not reflected due to the low resolution of the map.

3.4. Verification of SIND Model. A corresponding wave height with 100-year frequency was entered for a model verification, and the results were compared with the hazard map at the same conditions: 100-year frequency of wave height. Shape similarity was used to calculate the accuracy of the SIND model. The wave height of 100-year frequency was calculated by regression equation.

3.4.1. Threshold of Shape Similarity. A threshold is needed to determine whether two shapes are similar or not. In the CRITIC method, a subjective judgment process is necessary to calculate a threshold value. The matching pairs are directly divided into exact-matching and mismatching. The shape similarity of each matching pair is analyzed to estimate the threshold (see Figure 8). If the classification is well, the shape similarity values of the exact-matching pairs will generally be high and those of the mismatching pairs will be low. The threshold is defined as the value where the number of mismatching exceeds it of exact-matching. After the 3 maps used in derivation process were separated into exactmatching and mismatching, the shape similarity was analyzed. As a result, exact-matching pairs had a generally high shape similarity. The threshold where number of mismatching pairs exceeds those of exact-matching pairs is 0.55 (see Figure 9). 


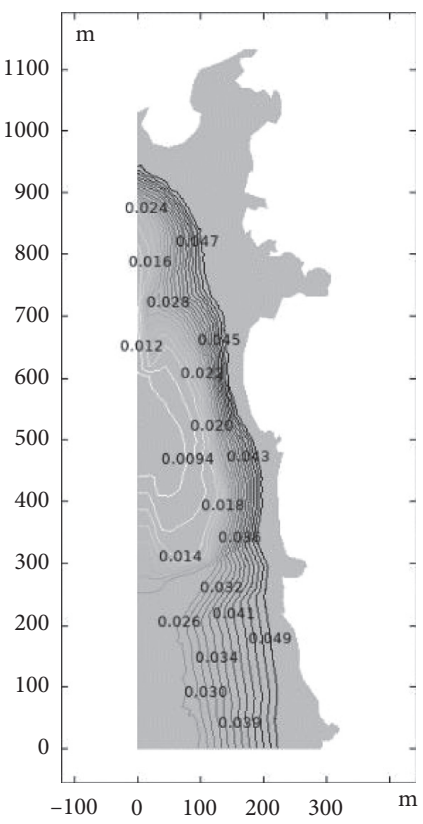

(a)

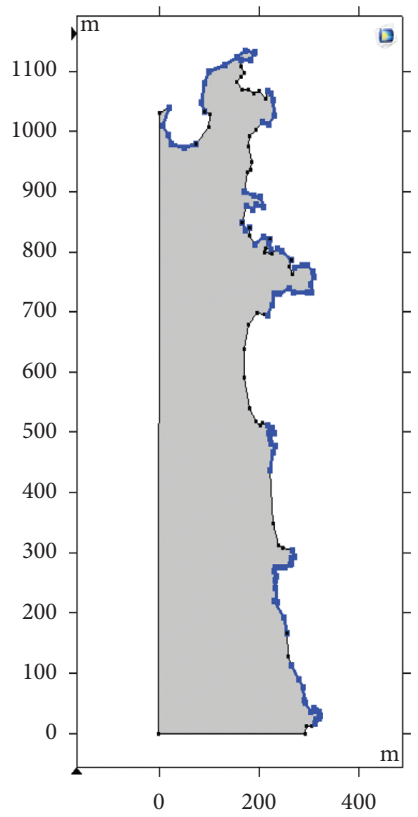

(c)

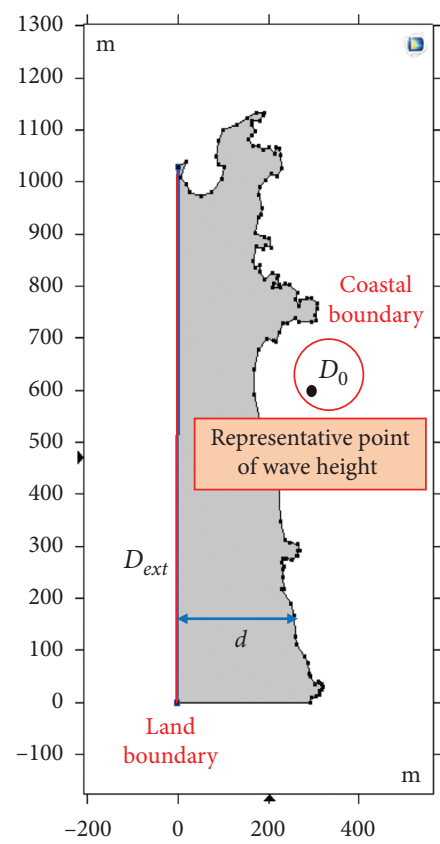

(b)

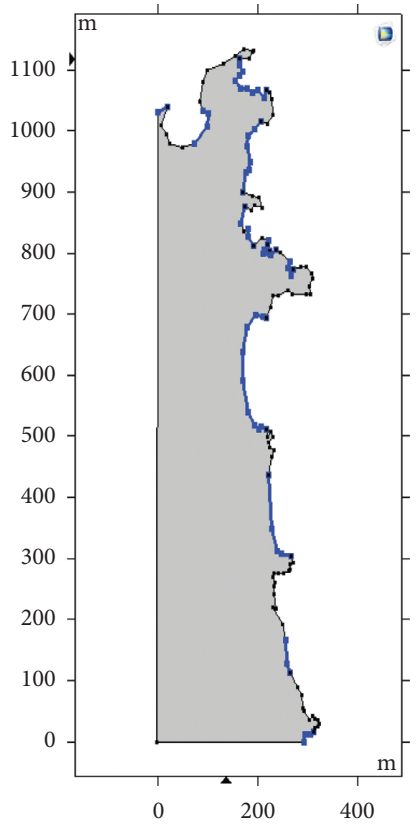

(d)

FIGURE 5: Coefficient and boundary conditions in the SIND model: (a) resistance coef; (b) B.C; (c) section A; (d) section B.

3.4.2. Results of Verification. It is necessary to obtain the accuracy of the area, center of gravity, and perimeter of each matching pair before calculating the overall shape similarity. Determination coefficients, root mean square error (RMSE), and Nash-Sutcliffe efficiency (NSE) were used for estimating indexes of shape characteristics. The determination coefficient is an index for evaluating the relationship between the observations and the model for the same variable. As a value is closer to 1.0 from 0.0 , it indicates that the model results fit the observative values well. Nash-Sutcliffe efficiency is an index that is used as much as the determination coefficient.
The Nash-Sutcliffe efficiency is a technique that evaluates the efficiency of the model using the relationship between observations and the model. Ramanarayanan et al. [35] suggested the determination coefficient and the Nash-Sutcliffe efficiency when they simulate the natural phenomenon such as rainfall and temperature. If the determination coefficient was a value of 0.5 or more and the Nash-Sutcliffe efficiency is 0.4 or more, the model can be well-conducted. The root mean square error is a technique for calculating the amount of error, and it is the most intuitive and meaningful evaluation index. When it closed to 


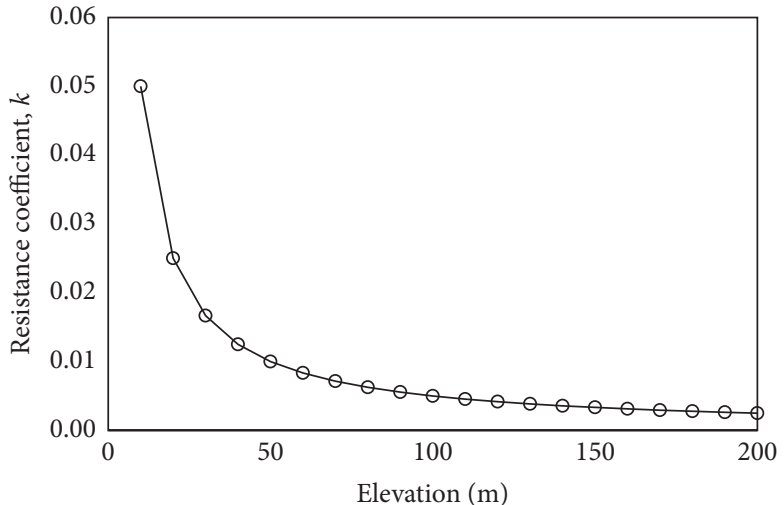

(a)

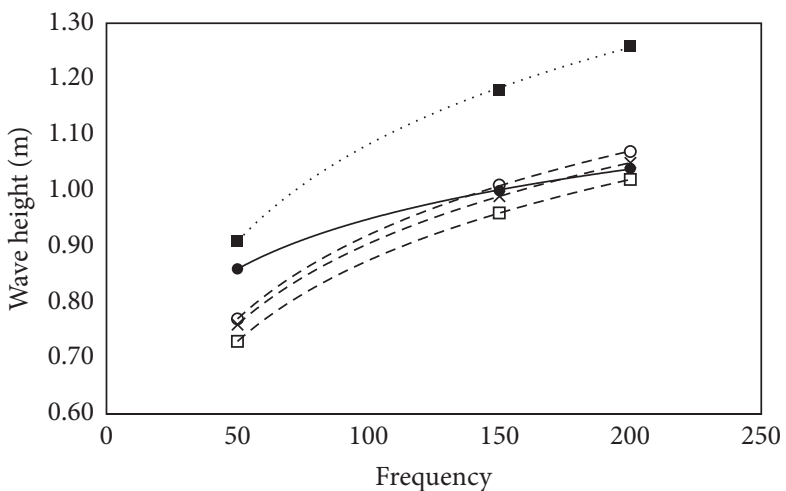

- BAJ1

- BAJ2

- BAJ3

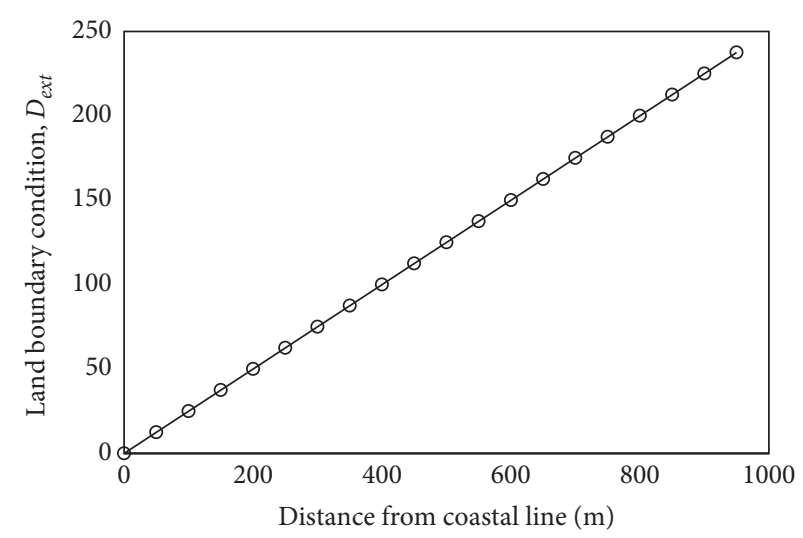

(b)

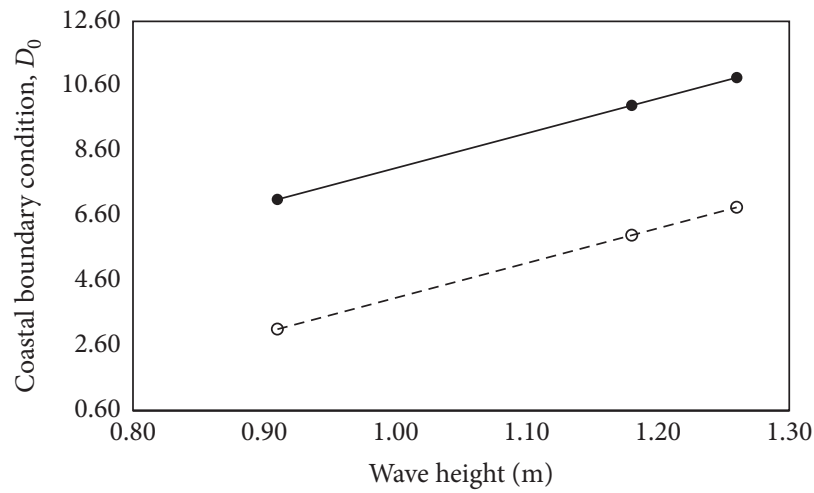

- Section A

- Section B

(c)

(d)

FIGURE 6: Results of coefficient and boundary conditions: (a) resistance coefficient with elevation; (b) land boundary conditions with d; (c) wave height with frequency; (d) coastal boundary conditions with $\mathrm{H}$.

TABLE 3: Results of overall shape similarity (S).

\begin{tabular}{lccc}
\hline & 50 -year & 150 -year & 200 -year \\
\hline Total matching pairs & 38 & 50 & 45 \\
$>0.6$ & 28 & 31 & 30 \\
Rate $(\%)$ & 73.7 & 62.0 & 66.7 \\
\hline
\end{tabular}

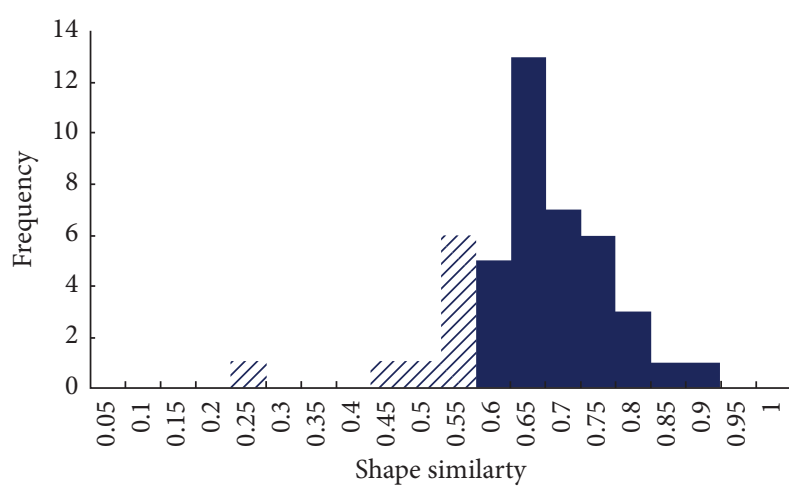

(a)

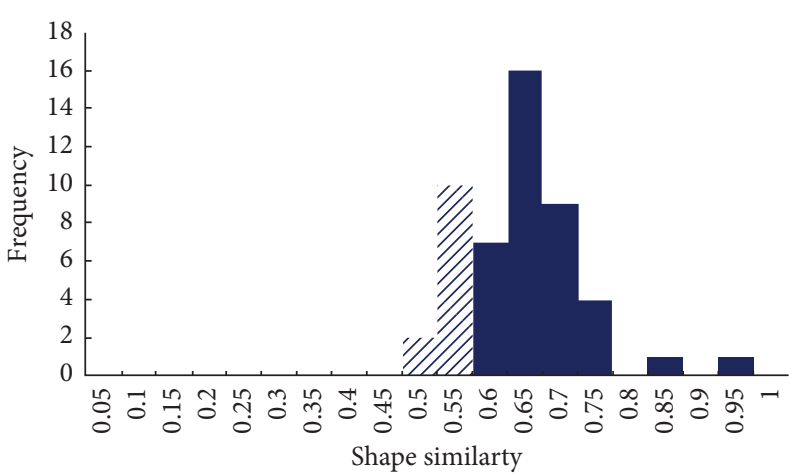

(b)

Figure 7: Continued. 


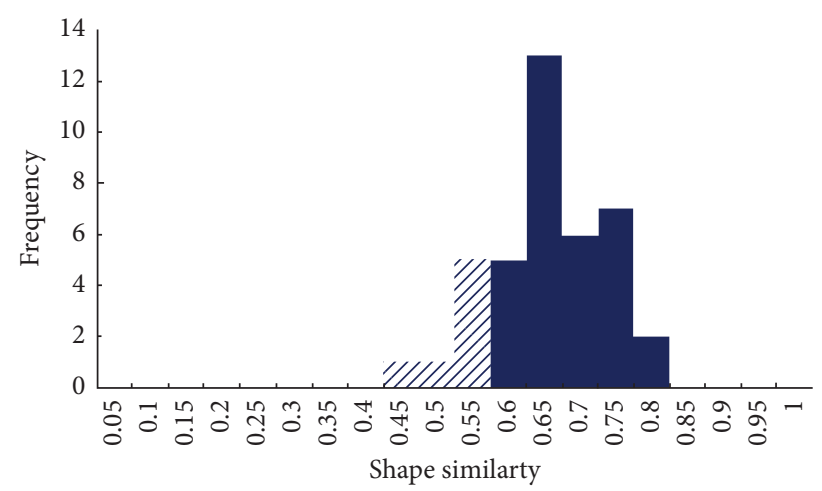

(c)

FIGURE 7: Results of shape similarity for each frequency: (a) 200-year; (b) 150-year; (c) 50-year.

TABLE 4: Overall results of the SIND model.

\begin{tabular}{|c|c|c|c|c|c|c|c|c|}
\hline \multirow{2}{*}{ Grade } & \multirow{2}{*}{ Distance between center of gravity } & \multicolumn{3}{|c|}{ Area $\left(\mathrm{km}^{2}\right)$} & \multirow{2}{*}{ Perimeter $(\mathrm{km})$} & \multirow{2}{*}{ Ratio of overlapped area } & \multicolumn{2}{|c|}{ Shape index } \\
\hline & & Each & Sum & Intersect & & & Each value & Difference \\
\hline $\begin{array}{l}\text { b1RA* } \\
\text { b1CA }\end{array}$ & 19.1 & $\begin{array}{l}0.056 \\
0.038\end{array}$ & 0.076 & 0.018 & $\begin{array}{l}0.007 \\
0.006\end{array}$ & 0.611 & $\begin{array}{l}8.10 \\
8.49\end{array}$ & 0.39 \\
\hline $\begin{array}{l}\text { b2RA } \\
\text { b2CA }\end{array}$ & 176.5 & $\begin{array}{l}0.029 \\
0.035\end{array}$ & 0.051 & 0.013 & $\begin{array}{l}0.005 \\
0.006\end{array}$ & 0.601 & $\begin{array}{l}8.50 \\
9.37 \\
\end{array}$ & 0.87 \\
\hline $\begin{array}{l}\text { b3RA } \\
\text { b3CA }\end{array}$ & 124.7 & $\begin{array}{l}0.008 \\
0.015 \\
\end{array}$ & 0.021 & 0.002 & $\begin{array}{l}0.003 \\
0.003\end{array}$ & 0.833 & $\begin{array}{l}9.05 \\
6.55\end{array}$ & 2.51 \\
\hline $\begin{array}{l}\mathrm{b} 4 \mathrm{RA} \\
\mathrm{b} 4 \mathrm{CA}\end{array}$ & 14.9 & $\begin{array}{l}0.006 \\
0.013\end{array}$ & 0.018 & 0.001 & $\begin{array}{l}0.002 \\
0.002\end{array}$ & 0.857 & $\begin{array}{l}6.63 \\
4.26\end{array}$ & 2.37 \\
\hline $\begin{array}{l}\text { b5RA } \\
\text { b5CA }\end{array}$ & 47.8 & $\begin{array}{l}0.003 \\
0.034\end{array}$ & 0.006 & 0.001 & $\begin{array}{l}0.001 \\
0.001\end{array}$ & 0.126 & $\begin{array}{l}6.85 \\
1.84\end{array}$ & 5.02 \\
\hline
\end{tabular}

"b1RA-1st Grade in "A" section of "b" area of hazard map (1: risk grade; R: hazard map; C: results of SIND; A, b: name of area).

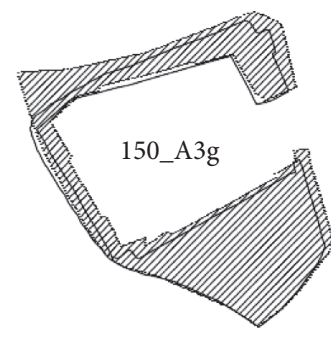

$\square$ Hazard map EIIJ SIND model

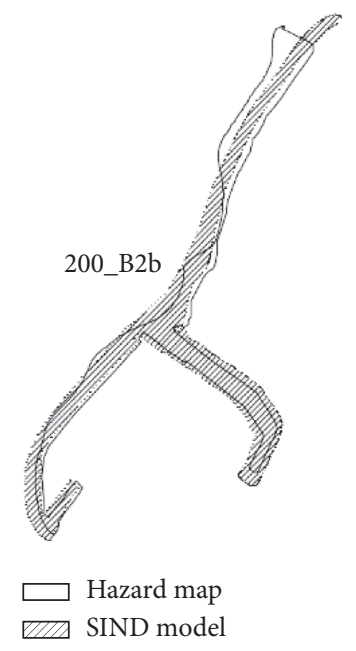

(b)

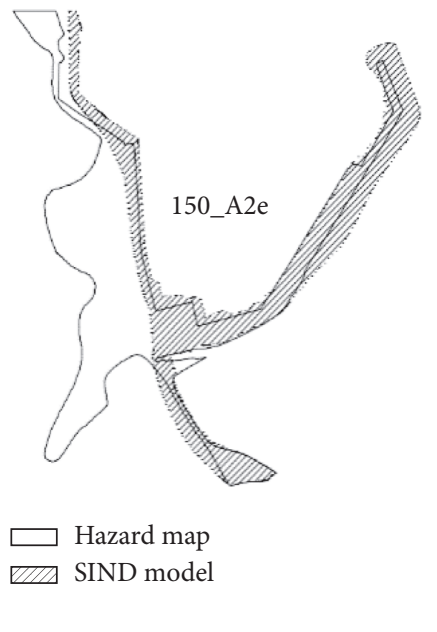

(c)

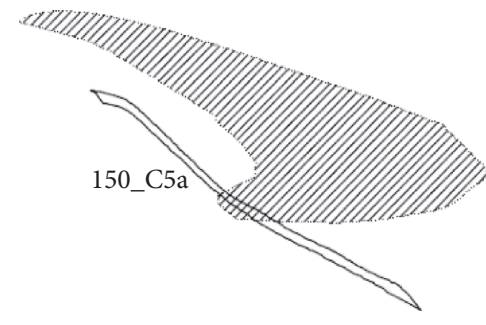

$\square$ Hazard map

(d)

Figure 8: Examples of exact-matching and mismatching objects: (a) Exact 1; (b) Exact 2; (c) Mis 1; (d) Mis 2.

0.0 , it has higher accuracy between model and observation. Each value of the shape characteristics at 100-year frequency condition is shown in Table 5 and Figure 10.

The accuracy of the results was verified at the random condition by using the thresholds. The shape similarity was calculated by matching the results with the hazard map for the wave height of 100-year frequency condition (see Table 6). A total of 41 pairs of matching pairs were made, and it was determined whether the shapes were similar based on the threshold. The number of exact-matching pairs was 33 


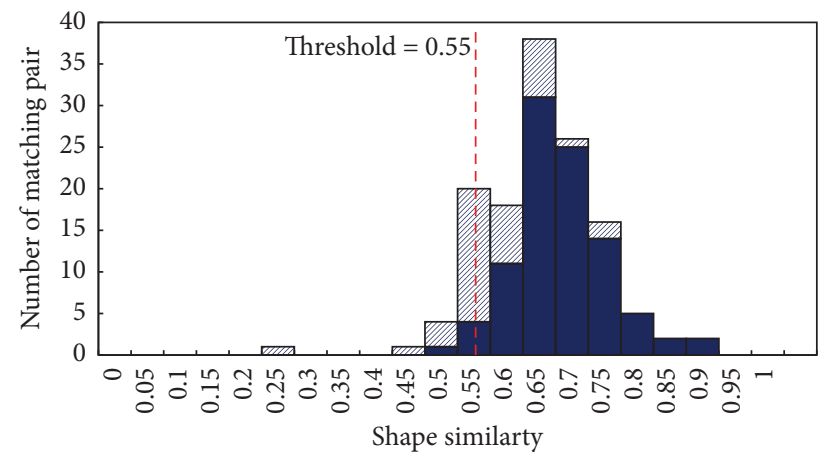

- Mismatching

- Exact-matching

FIgUre 9: Threshold of the SIND model.

TABLE 5: Estimation of shape parameter.

\begin{tabular}{lccc}
\hline Evaluation method & \multicolumn{2}{c}{ Center of gravity } & $A\left(\mathrm{~km}^{2}\right)$ \\
\hline$R^{2}$ & $x(\mathrm{~km})$ & $y(\mathrm{~km})$ & 0.8746 \\
RMSE & 0.9984 & 0.9986 & 0.0176 \\
NSE & 0.1937 & 0.1621 & 0.9061 \\
\end{tabular}

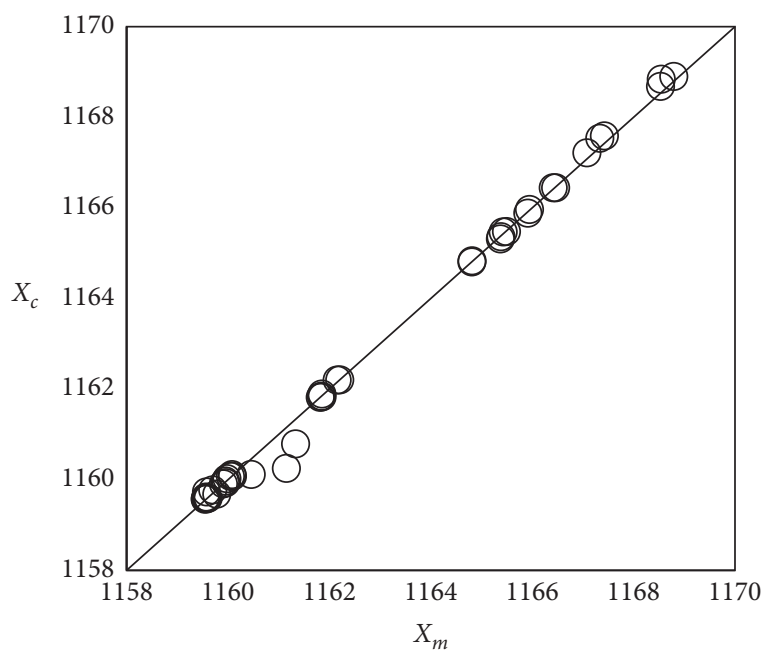

(a)

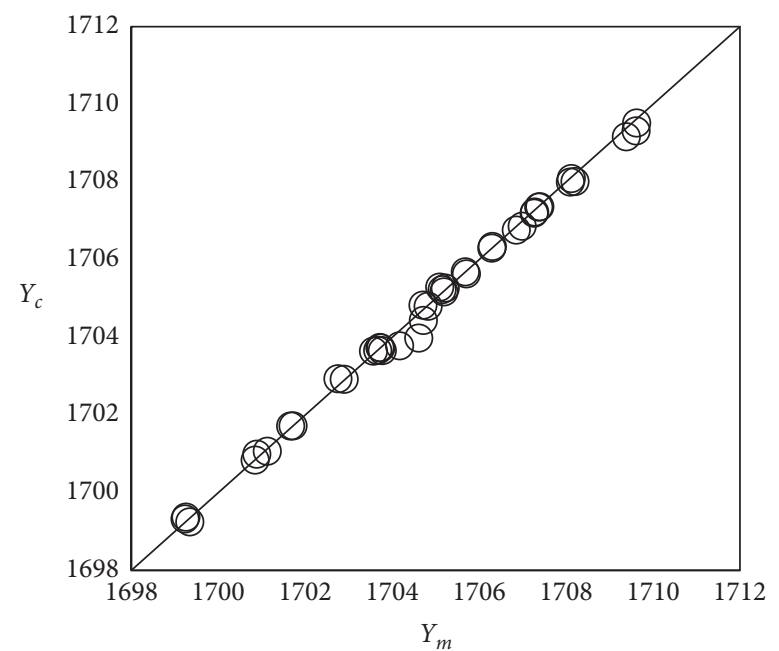

(b)

Figure 10: Continued. 


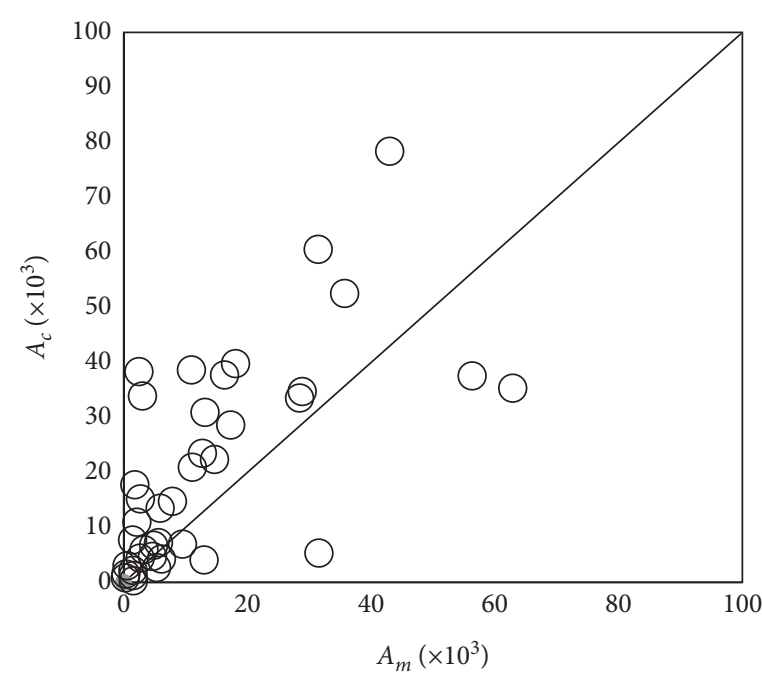

(c)

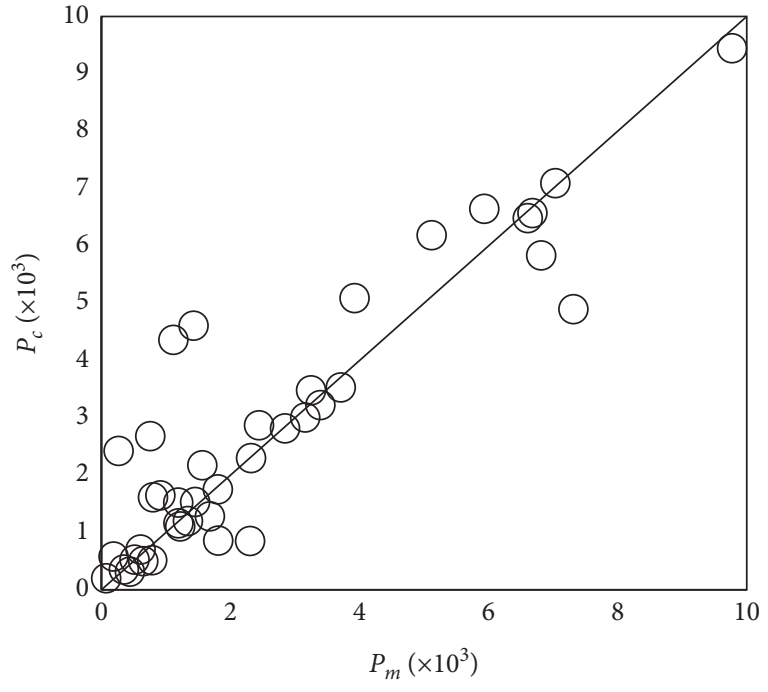

(d)

Figure 10: Scatter plot of (a) $x$-coordinate; (b) $y$-coordinate; (c) area; (d) perimeter.

TABLE 6: Estimation of shape similarity.

\begin{tabular}{llllr}
\hline Grade & SP & SA & SR & S \\
\hline $\begin{array}{l}\text { b1RA } \\
\text { b1CA }\end{array}$ & 0.987 & 0.411 & 0.986 & 0.720 \\
\hline $\begin{array}{l}\text { b2RA } \\
\text { b2CA }\end{array}$ & 0.883 & 0.421 & 0.973 & 0.685 \\
\hline $\begin{array}{l}\text { b3RA } \\
\text { b3CA }\end{array}$ & 0.917 & 0.198 & 0.924 & 0.584 \\
\hline $\begin{array}{l}\text { b4RA } \\
\text { b4CA }\end{array}$ & 0.990 & 0.174 & 0.926 \\
\hline $\begin{array}{l}\text { b5RA } \\
\text { b5CA }\end{array}$ & 0.968 & 0.879 & 0.847 & 0.599 \\
\hline
\end{tabular}

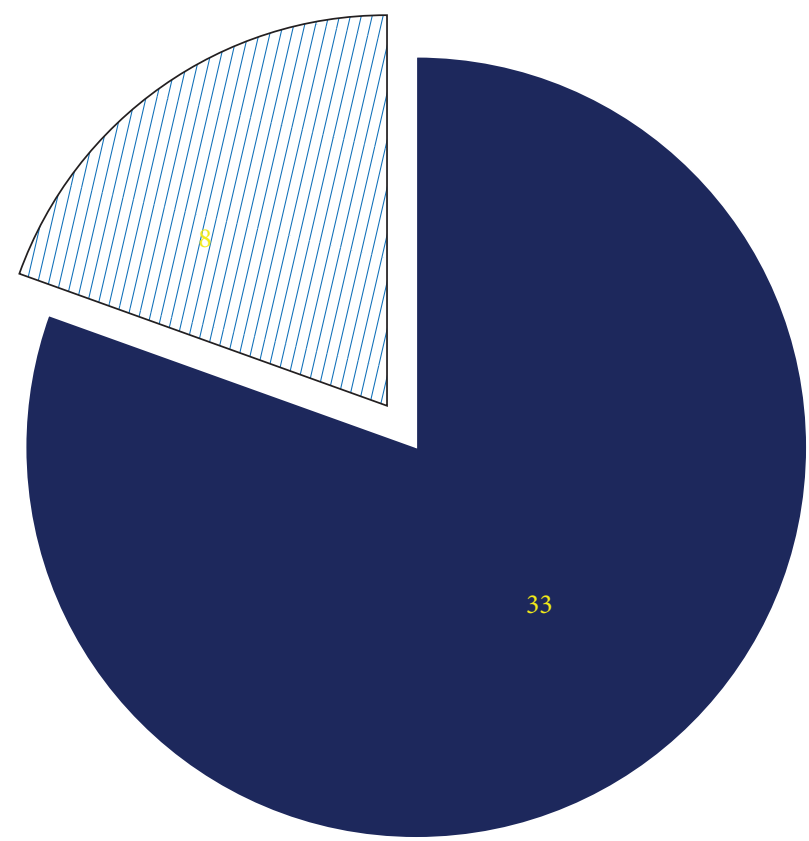

Exact-matching

Mismatching

FIGURE 11: Verification results. 
pairs. Thus, the accuracy is about $80.5 \%$. Figure 11 shows the number of exact-matching and mismatching classified by the threshold.

\section{Conclusions}

Parallel to the hazard map made by the MLTMA [32], the SIND model, based on a scientific interpolation method, was devised with the guarantee of rapid and accurate estimation. The spatial distribution of the risk grades for inundation was presented after verification estimated with shape similarity between official hazard map and results from this model.

We reflect the physical characteristics of the disaster due to storm surge into this model by selecting PDE form as governing equation and setting the simple input and boundary conditions. The wave height, which is a representative input value, appears to be simple and robust, but it is calculated by the KOSY that can take into account the effects of tide, wind, and pressure fluctuations. And we used the trial and error method to decide coefficients of governing equation for storm surge. Thus, it can predict risk grades for all disaster scenarios with high accuracy and speed. The user can find out hazardous area within a few seconds (about 5 seconds) in any condition between 50-year and 200-year frequency of wave heights. As a result, this model can make up for the limits of scenario-based disaster countermeasures. The advantages of this model can be summarized in terms of convenience, speed, and accuracy. User does not require a complicated understanding of disaster mechanism. And there is no need for cornerstone work before simulating the numerical model. Thus, they can easily yield the results in the right time and right condition for the right decision making. Although the model was performed by simple procedures, it has a physical meaning reflected the disaster characteristics including initial wave height and geographical resistance. This model also improved computation time. As mentioned, it takes approximately 5 seconds for about $720,000 \mathrm{~km}^{2}$ to present each hazard map while the Delft3D used commonly takes about 2 days in the same condition. And the accuracy of this model was about $80 \%$ for arbitrary condition. However, since we decided the threshold values under empirical estimations by classifying the exactmatching and mismatching, it is essential to prescribe the exact-matching and the mismatching through the clear criteria. And we would calibrate narrowly and adjust carefully multiobjects corresponding to one object so that the shape similarity will increase overall.

The SIND model shows the new approach of disaster prediction using the interpolation method with PDE representing physical characteristics of the target phenomenon. This model extenuated the complexity of the prediction for storm surge such as long simulation time and the occurrence of uncertain disasters, which were the well-known limitations in numerical modelling. Therefore, it is possible to predict disaster risk grades much quickly using this model, which should be very helpful for policy decisions to respond disaster. In fact, an early warning is very important to reduce human injury and property damage just prior to and immediately after occurrence of any event of specific disaster. Thus, the
SIND model is capable of amply accurate and much rapid predicting at the early stage. Also, it is based on database like hazard maps, which can be composed of structured, semistructured, and unstructured data. Therefore, it will be applicable to various disasters if more reliable database is acquired and higher accuracy is promised in the future.

And because this model used the results from numerical simulation or observation as input data for the scientific interpolation method, it does not consider the nonstationary of historical data. However, the historical data related to topography and climate are affected by extreme events as earthquakes. For instance, the change of topography will affect the occurrence of storm surge with physical laws. Thus, future works include the method how to regenerate risk grade considering such historical data.

\section{Data Availability}

The data used to support the findings of this study are available from the corresponding author upon request, and some of them would be restricted because of external security issues.

\section{Conflicts of Interest}

The authors declare that they have no conflicts of interest regarding the publication of this paper.

\section{Acknowledgments}

This work was supported by Korea Environment Industry \& Technology Institute (KEITI) through Water Management Research Program, funded by Korea Ministry of Environment (127572).

\section{References}

[1] S. Cutter, Vulnerability to Environmental Hazards, Progress in Hyman Geography, Thousand Oaks, CF, USA, 1957.

[2] M. K. Lindell and C. S. Prater, "Assessing Community Impacts of Natural Disasters," Natural Hazards Review, vol. 4, no. 4, p. 176, 2003.

[3] National Institute for Disaster Prevention, A Study on the Regional Vulnerability Assessment and its Application for the Disaster Management, National Emergency Management Agency, Seoul, Republic of Korea, 2003.

[4] Seoul Development Institute, Developing a Risk Assessment Method for the Mitigation of Urban Disasters, Seoul Metropolitan City, Seoul, Korea, 2009.

[5] W. C. Conner, R. H. Kraft, and D. L. Harris, "Empirical methods for forecasting the maximum storm tide due to hurricanes and other tropical storms," Monthly Weather Review, vol. 85, no. 4, pp. 113-116, 1957.

[6] D. L. Harris, An Interim Hurricane Storm Surge Forecasting Guide, US Department of Commerce, Washington, DC, USA, 1959.

[7] J. Proudman, "Note on the dynamics of storm-surges," Geophysical Journal International, vol. 7, pp. 44-48, 1954.

[8] A. T. Doodson, "Tides and storm-surges in a long uniform gulf," Proceedings of the Royal Society of London. Series A, vol. 237, no. 1210, pp. 325-343, 1956. 
[9] N. S. Heaps, "Storm surges on a continental shelf. Phil. Trans. R. Soc. Lond. A," Mathematical and Physical Sciences, vol. 257, no. 1082, pp. 351-383, 1965.

[10] R. H. Simpson and H. Riehl, The Hurricane and its Impact, Louisiana State University Press, Baton Rouge, LA, USA, 2015.

[11] T. S. Murty, Storm Surges: Meteorological Ocean Tide, p. 897, Department of Fisheries and Oceans, Ottawa, Canada, 1984.

[12] D. T. Pugh, Tides, Surges and Mean Sea-Level: A Handbook for Engineers and Scientists, p. 472, John Wiley, Hoboken, NJ, USA, 1987.

[13] N. S. Heaps, "Storm surges, 1967-1982," Geophysical Journal International, vol. 74, no. 1, pp. 331-376, 1983.

[14] J. Wolf, K. P. Hubbert, and R. A. Flather, A Feasibility Study for the Development of a Joint Surge and Wave Model, Proudmen Oceanographic Laboratory, Liverpool, UK, 1988.

[15] H. L. Tolman, "“Wind wave propagation in tidal seas," Communications on Hydraulic and Geotechnical engineering," Delft Univ. of Techn., Rep.vol. 90, no. 1, 1990.

[16] C. Mastenbroek, G. Burgers, and P. A. E. M. Janssen, "The Dynamical coupling of a wave model and a storm surge model through the atmospheric boundary layer," Journal of Physical Oceanography, vol. 23, no. 8, pp. 1856-1866, 1993.

[17] Y. S. Li and M. Y. Zhang, "Dynamic coupling of wave and surge models by Eulerian-Lagrangian method," Journal of Waterway, Port, Coastal, and Ocean Engineering, vol. 123, no. 1, pp. 1-7, 1997.

[18] J. Ozer, R. Padilla-Hernandez, J. Monbaliu et al., "A coupling module for tides, surges and waves," Coastal Engineering, vol. 41, no. 1-3, pp. 95-124, 2000.

[19] M. Peng, L. Xie, and L. J. Pietrafesa, "A numerical study of storm surge and inundation in the Croatan-AlbemarlePamlico Estuary System," Estuarine, Coastal and Shelf Science, vol. 59, no. 1, pp. 121-137, 2004.

[20] P. D. Bates and A. P. J. De Roo, "A simple raster-based model for flood inundation simulation," Journal of Hydrology, vol. 236, no. 1-2, pp. 54-77, 2000.

[21] R. J. Nicholls, "Rising sea levels: potential impacts and responses," in Global Environmental Change: Issues in Environmental Science and Technology, R. Hester and R. M. Harrison, Eds., vol. 17, pp. 83-107, Royal Society of Chemistry), Cambridge, UK, 2002.

[22] I. Brown, "Modelling future landscape change on coastal floodplains using a rule-based GIS," Environmental Modelling \& Software, vol. 21, no. 10, pp. 1479-1490, 2006.

[23] M. J. Purvis, P. D. Bates, and C. M. Hayes, "A probabilistic methodology to estimate future coastal flood risk due to sea level rise," Coastal Engineering, vol. 55, no. 12, pp. 1062-1073, 2008.

[24] J. Yim and G. Lee, "Estimating urban temperature by combining remote sensing data and terrain based spatial interpolation method," Journal of the Korean Cartographic Association, vol. 17, no. 2, pp. 75-88, 2017.

[25] T. Ishida and S. Kawashima, "Use of cokriging to estimate surface air temperature from elevation," Theoretical and Applied Climatology, vol. 47, no. 3, pp. 147-157, 1993.

[26] N. Fitria, Kajian Bahaya Tsunami Pada Variasi Ketinggian Run-Up Dan Arah Tsunami, Artikel PIT MAPIN VII, Bandung, Indonesia, 2008.

[27] F. Islam, S. Subiyanto, and L. M. dan Sabri, "Penentuan resiko dan kerentanan tsunami di kebumen dengan citra alos," Jurnal Geodesi, vol. 3, no. 1, pp. 141-154, 2014.

[28] I. Maemunah, C. Sulaeman, and R. dan Robiana, "Identifikasi potensi kerawanan tsunami di wilayah Kabupaten Jember,
Jawa Timur," Jurnal Lingkungan Dan Bencana Geologi, vol. 2, no. 2, pp. 141-152, 2011.

[29] Y. Fauzi and Z. M. Mayasari, "The run up tsunami modeling in bengkulu using the spatial interpolation of kriging technique," Forum Geografi, vol. 28, no. 2, pp. 103-112, 2014.

[30] J. E. Lee, 3-Dimensional Object Reconstruction of Medical Images Using Kriging and Markov Random Field Model, Ewha University, Seoul, South Korea, 1996.

[31] D. H. Kim, H. J. Yoo, S. I. Jeong, and S. O. Lee, "Development for prediction model of disaster risk through try and error method: storm surge," Journal of Korean Society of Disasters and Security, vol. 11, no. 2, pp. 37-43, 2018.

[32] D. Y. Lee, Development of Storm Surge and Tsunami Prediction System and Estimation of Design Water Level for Major Ports in Korea, Ministry of Land, Transport and Maritime Affairs, Korea Ocean Research \& Development Institute, Busan, Korea, 2006.

[33] C. O. M. S. O. L. Multiphysics, Introduction to COMSOL Multiphysics ${ }^{\circledR}$, COMSOL Multiphysics, Burlington, MA, USA, 1998.

[34] J. Y. Kim, Y. Huh, D. S. Kim, and K. Y. Yoo, “A new method for automatic areal feature matching based on shape similarity using CRITIC method," Journal of the Korean Society of Surveying, Geodesy, Photgrammetry, and Cartography, vol. 29, no. 2, pp. 113-121, 2011.

[35] T. S. Ramanarayanan, J. R. Williams, W. A. Dugas, L. M. Hauck, and A. M. S. McFarland, Using APEX to Identify Alternative Practices for Animal Waste Management, ASAE Paper, Washington, DC, USA, 1997. 